\title{
Effect of cage enrichment on the welfare of farmed foxes ${ }^{1)}$
}

\author{
STANISŁAW ŁAPIŃSKI*, SYLWIA PAŁKA, DANUTA WROŃSKA**, IWONA GUJA***, \\ ANDRZEJ ZOŃ****, PIOTR NIEDBAŁA*, SVETLANA N. SERGINA***** \\ Department of Genetics and Animal Breeding, *Institute of Animal Sciences, \\ **Department of Animal Physiology and Endocrinology, Faculty of Animal Sciences, \\ University of Agriculture in Krakow, Adama Mickiewicza 24/28, 30-059 Krakow, Poland \\ ***Department of Ichthyobiology and Fisheries, Faculty of Animal Sciences, \\ University of Agriculture in Krakow, Prof. Teodora Spiczakowa 6, 30-149 Krakow, Poland \\ ****Experimental Station in Chorzelow, National Research Institute of Animal Production in Balice n. Krakow, \\ 39-331 Chorzelow 771, Poland

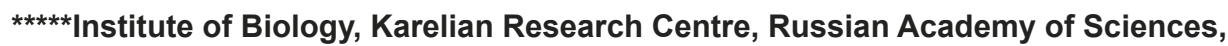 \\ Pushkinskaya 11, 184910 Petrozavodsk, Russia
}

\section{Łapiński S., Pałka S., Wrońska D., Guja I., Zoń A., Niedbała P., Sergina S. N. Effect of cage enrichment on the welfare of farmed foxes}

\section{Summary}

The aim of the study was to use behavioural and cortisol tests to determine whether cage enrichment (observation shelves, wooden sticks for gnawing) improves the welfare of farmed foxes (Vulpes vulpes). The paper discusses welfare criteria such as "expression of other behaviours", "good human-animal relationships" and "positive emotional state". The study covered 60 young foxes. After weaning, the animals were placed in standard cages, two individuals per cage. The foxes were divided into three groups. In the control group, no additional cage enrichment was provided. Group I was provided with observation shelves; group II was provided with wooden gnawing sticks. During the experiment the foxes underwent repeated tests: empathic test, feeding test and salivary cortisol test. The data obtained were analysed statistically (ANOVA, Tukey's test, correlation), taking into account the following variables: the impact of cage enrichment, animal gender, temperament, and colour mutation. The study did not show conclusively that the use of cage enrichment affects animal temperament or the level of cortisol. However, in the group with gnawing sticks, the level of cortisol in the second measurement was significantly lower in comparison with other groups. This indicates that satisfying the need to gnaw objects reduces stress in foxes. The study showed a high correlation between the empathic and the feeding test, both of which are useful for testing the emotional state of foxes and the human-animal relationship.

Keywords: red fox, Vulpes vulpes, welfare, behaviour, cortisol test, behavioural tests

The first silver foxes, which are colour mutations of red foxes (Vulpes vulpes), were kept on farms around 100 years ago, but large-scale fur farms housing hundreds of animals for commercial purposes have been in use for only approximately 60 years. In comparison with species such as sheep, cattle, horses, dogs, or pigs, all of which have been kept in captivity for more than 5,000 years (4), foxes have come into contact with humans only recently. Thus many questions have arisen with regard to the domestication of these animals and the assessment of their welfare under farm conditions.

1) The study was carried out under statutory activity supported by the Ministry of Science and Higher Education, No. DS.3266/2017/ZHTChDI.
Silver foxes are agile and exhibit a variety of exploratory behaviours. They readily interact with their environment and spend up to $30-40 \%$ of their daily time performing a variety of activities (7). Observations have revealed that foxes regularly nibble and gnaw available objects (e.g. wooden sticks) or elements of the cage interior, such as nest boxes, shelves or food trays (8). The propensity for exploration and oral manipulation is linked to the biology of this species: as opportunistic hunters and scavengers, foxes are more likely to display intrinsic motivation for exploration and foraging (hunting) (2).

The WelFur project was launched by the European Fur Breeders' Association (EFBA) in 2009. The main 
aim of the project is to develop on-farm welfare assessment protocols for farmed foxes (blue fox, silver fox) and mink (9). The WelFur protocols apply four welfare principles (good feeding, good housing, good health, and appropriate behaviour) and 12 welfare criteria defined in the Welfare Quality ${ }^{\circledR}$ project (11).

The principle of appropriate behaviour includes four criteria: expression of social behaviours, expression of other behaviours, good human-animal relationships, and positive emotional state (12).

The purpose of this study was to use behavioural and cortisol tests to verify the hypothesis that the enrichment of cages (observation shelves, wooden sticks for gnawing) improves foxes' welfare (Vulpes vulpes). The paper discusses the expression of other behaviours (the opportunity to use enrichment or observe surroundings), good human-animal relationships (feeding test), and positive emotional state (temperament test).

\section{Material and methods}

The study, which covered 60 young foxes, was conducted from 29 June to 13 September 2016 at the Experimental Station in Chorzelow - part of the National Research Institute of Animal Production (Poland). After weaning, the animals were placed in standard cages, two individuals per cage (mostly siblings, male and female). The foxes were divided into three groups consisting of 20 individuals (10 cages). In the control group, no additional cage enrichment was provided. Group I was provided with observation shelves; group II was provided with wooden gnawing sticks. Additional enrichments were introduced on 5 July.

During the experiment the foxes underwent repeated tests: empathic test (four times, on 29.06, 6.07, 2.08 and 13.09), feeding test (twice, on 30.06 and 7.09) and salivary cortisol test (three times, on 4.07, 16.07 and 12.09).

The empathic test (3) was used to determine the foxes' temperament. The test is considered to be a non-invasive and very precise tool; it consists in putting a stick with a bow on one end into the cage through a net perforation, without opening the door. The stick is placed at the level of the animal's nose in its range of sight. The person performing the test stands about $50 \mathrm{~cm}$ away from the cage. The observation lasts 15-20 seconds and relates to the first reaction of the animal to something new that does not raise excessive fear. The observer concentrates on thorough observation of the animal's behaviour and tries to understand its situation. This makes it possible to evaluate the natural temperament of the animal without introducing additional stress stimuli (1). In order to calculate the average temperament, the following scale was adopted: 1 = aggressive, 2 = fearful, $3=$ confident.

Based on the test results, foxes subjected to observation were divided into three categories: aggressive $(\mathrm{A},<1.75)$, fearful (F, 1.75-2.25) and confident (C, > 2.25).

The feeding test included observations of the type of reaction to feed placed in the trough located on the front wall of the cage. Animals' reactions were monitored for approx. 1 minute (observation of the front of the cage). Analysis of the results obtained in the feeding test enabled classification of the foxes into two groups: trustful (foxes which in the presence of humans approached the trough and ate the feed: score 1) and fearful (foxes which within 1 minute did not approach the trough and did not start to eat the feed: score 0).

For the cortisol test, samples of saliva were collected from the animals at the Experimental Station in Chorzelow. Cortisol levels in saliva (DRG ${ }^{\circledR}$ Salivary Cortisol SLV-2930) were measured at the laboratory of the Department of Animal Physiology, University of Agriculture in Krakow (Poland).

The data obtained were analysed statistically (ANOVA, Tukey's test, correlation) using Statistica 12.5 (StatSoft 2015), taking into account the following variables: the impact of cage enrichment, animal gender, temperament, and colour mutation.

\section{Results and discussion}

Analysis of the research data did not show statistically significant differences between groups and measurements obtained from subsequent empathic tests. The mean temperament coefficient of the examined foxes amounted to $2.08(\mathrm{SD}=0.69)$; according to the scale, this corresponds to the fearful temperament. No statistically significant differences between males and females were detected (Tab. 1).

Statistically significant differences were detected in the salivary cortisol concentrations obtained in the second measurement as compared with the $1^{\text {st }}$ or $3^{\text {rd }}$ measurement. In contrast, no differences were found between the first and the third measurements. In the second measurement, there was a statistically significant difference between the control group and the group provided with gnawing sticks (Tab. 2). No statistically significant differences were observed between males and females in the individual measurements, or in the total result.

After averaging all results obtained from the empathic test, foxes were classified as aggressive $(n=17)$, fearful $(n=20)$, and confident $(n=23)$. There were no statistically significant differences between diverse animal temperaments and cortisol levels (Tab. 3).

The overall results received from the cortisol measurements did not significantly differ statistically for the individual types of temperaments. Moreover, in all cortisol measurements, statistical analysis failed to reveal any significant effect of fur colour mutation on the salivary cortisol level in the foxes (Tab. 4).

The overall result of all three cortisol measurements for each colour mutation was not statistically significant. However, the highest concentration was recorded for cross foxes and the lowest for white neck foxes.

Statistical evaluation of the overall results from the empathic test showed that the temperament of the foxes was significantly affected by the colour mutation $(\mathrm{P}<0.05)$. The platinum foxes were the most confident $(2.65, \mathrm{SD}=0.52)$, then crosses $(2.50, \mathrm{SD}=0.46)$ and white necks $(2.36, \mathrm{SD}=0.69)$. The pastel and silver 
foxes presented more fearful behaviour and obtained the average coefficient of temperament $1.93, \mathrm{SD}=$ 0.66 ; silver $1.85, \mathrm{SD}=0.69$ respectively.

Comparison of the results obtained from the emphatic test with the data from the feeding test revealed a significant correlation between animal temperament and the response to food stimuli $(\mathrm{r}=0.59, \mathrm{P}<0.01)$ : $6 \%$ of foxes classified as aggressive, $48 \%$ as fearful

Tab. 1. The temperament coefficient (empathic test) of foxes provided with different types of cage enrichment $(\overline{\mathbf{x}} \pm \mathrm{SD})$

\begin{tabular}{|l|c|c|c|c|c|}
\hline Group (enrichment) & $\mathrm{n}$ & Test I & Test II & Test III & Test IV \\
\hline Control & 20 & $2.10 \pm 0.72$ & $2.05 \pm 0.89$ & $2.15 \pm 0.93$ & $2.15 \pm 0.93$ \\
Shelf & 20 & $2.00 \pm 0.79$ & $2.00 \pm 0.86$ & $1.95 \pm 0.83$ & $2.05 \pm 0.83$ \\
Gnawing stick & 20 & $2.05 \pm 0.51$ & $2.05 \pm 0.83$ & $2.30 \pm 0.80$ & $2.10 \pm 0.85$ \\
Total & 60 & $2.05 \pm 0.67$ & $2.03 \pm 0.84$ & $2.13 \pm 0.85$ & $2.10 \pm 0.86$ \\
\hline
\end{tabular}

Explanations: test I - no cage enrichment; test II - 1 day with cage enrichment; test III - 26 days with cage enrichment; test IV - 60 days with cage enrichment; scale: 1 - aggressive, 2 - fearful, 3 - confident

Tab. 2. Concentration of cortisol $(\mathrm{ng} / \mathrm{mL})$ in saliva of foxes provided with different types of cage enrichment

\begin{tabular}{|l|c|c|c|c|c|c|}
\hline \multirow{2}{*}{ Group (enrichment) } & \multicolumn{2}{|c|}{ Cortisol I } & \multicolumn{2}{c|}{ Cortisol II } & \multicolumn{2}{c|}{ Cortisol III } \\
& $\mathrm{n}$ & $\overline{\mathrm{x}} \pm$ SD & $\mathrm{n}$ & $\overline{\mathrm{x}} \pm$ SD & $\mathrm{n}$ & $\overline{\mathrm{x}} \pm$ SD \\
\hline Control & 20 & $4.01 \pm 1.58$ & 20 & $5.64^{\mathrm{a}} \pm 1.45$ & 19 & $3.99 \pm 1.53$ \\
Shelf & 19 & $3.14 \pm 1.35$ & 20 & $5.06 \pm 1.10$ & 16 & $3.95 \pm 1.22$ \\
Gnawing stick & 20 & $4.28 \pm 2.55$ & 20 & $4.65^{\mathrm{b}} \pm 0.98$ & 17 & $3.70 \pm 1.01$ \\
Total & 59 & $3.82 \pm 1.94$ & 60 & $5.12 \pm 1.24$ & 52 & $3.88 \pm 1.27$ \\
\hline
\end{tabular}

Explanations: $\mathrm{a}, \mathrm{b}$ - different letters in columns indicate statistically significant differences $(\mathrm{P}<0.05)$; cortisol I - no cage enrichment; cortisol II - 10 days with cage enrichment; cortisol III - 69 days with cage enrichment

Tab. 3. Concentration of cortisol $(\mathrm{ng} / \mathrm{mL})$ in the saliva of foxes displaying different temperaments

\begin{tabular}{|l|c|c|c|c|c|c|}
\hline \multicolumn{1}{|c|}{ Group } & \multicolumn{2}{c|}{ Cortisol I } & \multicolumn{2}{c|}{ Cortisol II } & \multicolumn{2}{c|}{ Cortisol III } \\
& $\mathrm{n}$ & $\overline{\mathrm{x}} \pm \mathrm{SD}$ & $\mathrm{n}$ & $\overline{\mathrm{x}} \pm$ SD & $\mathrm{n}$ & $\overline{\mathrm{x}} \pm$ SD \\
\hline Aggressive & 16 & $3.50 \pm 2.00$ & 17 & $4.72 \pm 1.04$ & 15 & $3.78 \pm 1.00$ \\
Fearful & 20 & $3.99 \pm 2.19$ & 20 & $5.47 \pm 1.42$ & 16 & $4.06 \pm 1.48$ \\
Confident & 23 & $3.90 \pm 1.71$ & 23 & $5.10 \pm 1.17$ & 21 & $3.82 \pm 1.31$ \\
Total & 59 & $3.82 \pm 1.94$ & 60 & $5.12 \pm 1.24$ & 52 & $3.88 \pm 1.27$ \\
\hline
\end{tabular}

Explanations: cortisol I - no cage enrichment; cortisol II - 10 days with cage enrichment; cortisol III - 69 days with cage enrichment

Tab. 4. Concentration of cortisol $(\mathrm{ng} / \mathrm{mL})$ in the saliva of foxes with different fur colour mutations

\begin{tabular}{|l|r|r|r|r|r|r|}
\hline \multirow{2}{*}{ Group (enrichment) } & \multicolumn{2}{|c|}{ Cortisol I } & \multicolumn{2}{c|}{ Cortisol II } & \multicolumn{2}{c|}{ Cortisol III } \\
& \multicolumn{1}{|c|}{$\mathrm{n}$} & \multicolumn{1}{c|}{$\overline{\mathrm{x}} \pm$ SD } & \multicolumn{1}{|c|}{$\mathrm{n}$} & $\overline{\mathrm{x}} \pm$ SD & \multicolumn{1}{c|}{$\mathrm{n}$} & $\overline{\mathrm{x}} \pm$ SD \\
\hline Silver & 19 & $4.27 \pm 2.21$ & 20 & $5.23 \pm 1.60$ & 16 & $3.73 \pm 1.54$ \\
Cross & 4 & $5.11 \pm 3.64$ & 4 & $5.66 \pm 0.51$ & 4 & $4.62 \pm 1.13$ \\
Platinum & 5 & $3.39 \pm 1.57$ & 5 & $5.53 \pm 0.76$ & 5 & $3.15 \pm 1.71$ \\
Pastel & 21 & $3.60 \pm 1.57$ & 21 & $5.28 \pm 0.79$ & 18 & $3.80 \pm 1.00$ \\
White neck & 9 & $3.11 \pm 1.29$ & 9 & $4.00 \pm 1.26$ & 8 & $4.42 \pm 0.93$ \\
Total & 58 & $3.83 \pm 1.95$ & 59 & $5.11 \pm 1.25$ & 51 & $3.88 \pm 1.28$ \\
\hline
\end{tabular}

Explanations: as in Tab. 3 and $83 \%$ as confident started to eat in the presence of

Studies by other authors have demonstrated that enrichment of a cage with a platform does not substantially affect the reaction of farmed silver foxes to stressors, but it improves animal welfare by supporting the development of more complex behaviours and oped for the purpose of this study was based on the hypothesis of hyponeophagia, i.e. that fearful animals show reduced response to food stimuli when exposed to the presence of humans. The feeding test provides an accurate, reliable, and objective measure of fear of humans in farmed foxes. In the experiment with the blue and silver foxes, the fearful individuals displayed a higher level of stress, as assessed by using urinary cortisol. In silver foxes, similar changes were observed in the blood cortisol of unstressed animals and following administration of ACTH (10). However, the present experiment involving evaluation of salivary cortisol did not provide similar results. Fear in foxes can be reduced by selecting less fearful animals and promoting positive humananimal relationships. Enrichment of cages with nest boxes or platforms affects the behaviour of foxes to a lesser extent than altering the cage surroundings. Thus elements outside the cage should be considered an essential part of the environment of caged foxes (10).

The observed differences in the temperament of foxes with different colour mutations might be related to "domestication syndrome". Selection for tameness leads to reduction of neural crest-derived tissues of behavioural relevance via multiple pre-existing genetic variants that affect neural crest cell numbers at the final sites. As an unselected by-product, this neural crest hypofunction produces morphological changes in pigmentation, jaws, teeth, ears, etc. (13). Other investigations into fear reactions in relation to coat colour have 
been conducted on the American red fox (Vulpes vulpes fulvus) by Keeler at al. (5). It was shown that adrenal and thyroid functions were altered and fear reactions were modified by the presence of mutant coat colour genes. The average startle distance for wild reds was greater than that for other mutations (black, blue, amber, chocolate).

The present study did not show conclusively that cage enrichment influences animals' relations to humans or the level of cortisol in saliva. However, in the group provided with gnawing sticks, the level of cortisol in the second measurement was statistically significantly lower in comparison with other groups. This may indicate that satisfying the need to gnaw objects reduces stress in foxes.

The study showed a high correlation between the results obtained from the empathic test and the feeding test: both are useful tools for testing the emotional state of foxes and the human-animal relationship.

\section{References}

1. Fortuńska D., Barabasz B.: Using behavioural tests for temperament assessment in the raccoon dogs. Rocz. Nauk. Zoot. 2003, 30, 303-310.

2.Fox M. W.: The Wild Canids: Their Systematics, Behavioural Ecology and Evolution. Van Nostrand Reinhold, New York 1975.
3. Gacek $L$.: The proposal of new behavioural test for the polar fox. Empathic test. Scientifur 1999, 23, 201-205.

4.Hemmer H.: Domestikation: Verarmung der Merkwelt. Braunschweig/ Wiesbaden: Vieweg 1983.

5. Keeler C., Mellinger T., Fromm E., Wade L.: Melanin, adrenalin and the legacy of fear. J. Hered. 1970, 61, 81-88.

6. Korhonen H., Niemela P.: Temperament and reproductive success in farm-bred silver foxes housed with and without platforms. J. Anim. Breed. Genet. 1996, $113,209-218$

7. Mononen J., Harri M., Rekilä T.: Comparisons of preferences of farmed silver and blue foxes for cages with and without a nest box. Acta Agric. Scand. Sect. A. Anim. Sci. 1996, 46, 117-124.

8. Mononen J., Korhonen H., Harri M., Kasanen S.: A comparison of the use of resting platforms and nest boxes in growing farmed silver foxes (Vulpes vulpes). Appl. Anim. Behav. Sci. 1998, 58, 383-396.

9. Mononen J., Møller S. H., Hansen S. W., Hovland A. L., Koistinen T., Lidfors L., Malmkvist J., Vinke C. M., Ahola L.: The development of on-farm welfare assessment protocols for foxes and mink: the WelFur project. Anim. Welfare 2012, 21, 363-371.

10. Rekila T.: Behavioural tests in welfare research of foxes. Kuopio University Publications C. Natural Environ. Sci. 1999, 92, 1-52.

11. Veissier I., Botreau R., Perny P.: Scoring animal welfare: difficulties and Welfare Quality ${ }^{\circledR}$ solutions, [in:] Keeling L.: An Overview of the Development of the Welfare Quality ${ }^{\circledR}$ Project Assessment Systems. Welfare Quality Reports 2009, 15-32.

12. WelFur.: Welfare Assessment protocol for Foxes.: WelFur Consortium, Brussels, Belgium 2014

13. Wilkins A. S., Wrangham R. W., Fitch W. T.: The "Domestication Syndrome" in Mammals: A Unified Explanation Based on Neural Crest Cell Behavior and Genetics. Genetics 2014, 197, 795-808.

Corresponding author: Sylwia Palka Ing. PhD, al. Mickiewicza 24/28, 30-059 Krakow, Poland; e-mail: s.palka@ur.krakow.pl 